\title{
Sucroferric oxyhydroxide: A novel phosphate binder for the management of mineral bone disease in dialysis patients
}

\author{
Griveas I*, Sitaras P, Andriopoulos C and Aktsiali M \\ Private Dialysis Unit "Nefroiatriki” Athens, Greece
}

\begin{abstract}
Hyperphosphatemia is a hallmark of advanced chronic kidney disease (CKD) and associated with adverse outcomes. We aimed to investigate sucroferric oxyhydroxide (PA21) in terms of efficacy and safety in haemodialysis (HD) patients with MBD. In this prospective study HD stable patients with hyperphosphataemia were received PA21 for 24 weeks. The primary outcome was estimation of serum phosphate concentration at the end of treatment. Secondary outcomes were corrected serum calcium and intact-parathyroid hormone (PTH) concentrations. Ferritin levels were monitored also during our study period. Adverse events (AEs) and adverse drug reactions (ADRs) were evaluated. A total of $31 \mathrm{HD}$ patients were enrolled. We noticed significant reduction of the phosphate levels even from the first month of treatment. Remarkable finding was the significant reduction of PTH levels in all of our patients without interfering in vitamin D or calcimimetic supplementation after 6 months of therapy with PA21 which carried out until the end of the study protocol $(383 \pm 115 \mathrm{pg} / \mathrm{ml})$. Ferritin levels remained stable. 2 months since the beginning of the protocol we noticed increase in the levels of Hct which remained stable until the end of the study period (37.47\%). PA21 is a valuable treatment option for hyperphosphataemia in CKD patients on dialysis, providing an effective and generally well tolerated noncalcium-based phosphate binder therapy with a low pill burden and the potential for improved treatment adherence in MBD in general.
\end{abstract}

\section{Introduction}

Hyperphosphatemia is a hallmark of advanced chronic kidney disease (CKD) and associated with adverse outcomes. It results from the accumulation of phosphorus (ph) in the body from dietary phosphate intake and decreasing excretion of ph in the urine. Preclinical and epidemiological studies strongly support a causal relationship between hyperphosphatemia and mortality as well as cardiovascular complications, especially including vascular, valvular and soft-tissue calcifications [1-3].

The use of oral phosphate binders to reduce the absorption of dietary phosphate is the mainstay of therapy $[4,5]$. It has been reported that $88 \%$ of dialysis patients are prescribed phosphate binders [6]. Guidelines for CKD around the globe recommend apart from dietary restriction of phosphates and sufficient hemodialysis (HD), the use of phosphate-binding agents for the management of hyperphosphatemia in patients undergoing chronic dialysis [7-9]. In specific, phosphate binder use is necessary to inhibit the absorption of dietary phosphate from the gastrointestinal tract because dietary restriction and HD by themselves are insufficient to eliminate the ph excess in our western lifestyle. In addition, treatment with phosphate binders has been associated with improved survival among these patients [10,11].

It is to be noticed that chronic dialysis patients with persistent hyperphosphatemia suffer from a clinical entity called secondary hyperparathyroidism or mineral bone disease (MBD). To control hyperparathyroidism, most patients are also prescribed either oral or parenteral vitamin D receptor agonists (VDRAs). However, it is possible that the concomitant administration of phosphate binders with oral VDRAs may result in drug-drug interactions, thereby reducing the therapeutic activity of these oral VDRAs [12].

On the other hand, each phosphate binder has its own specific characteristics and disadvantages. Most common are calcium loading, high pill burden, gastrointestinal adverse drug reactions (ADRs), and accumulation of nonbiometals in organs [13-16]. It is obvious that the ideal phosphate binder would prevent these unfavorable properties and at the same time could favourably affect other significant parameters of $\mathrm{MBD}$ such as parathormone (PTH).

Sucroferric oxyhydroxide, referred to hereafter as PA21, is a novel, noncalcium, iron-based phosphate binder. According to literature data PA21 as a treatment for hyperphosphatemia in HD patients can help reduce the pill burden and increase adherence while maintaining efficacy [17-19]. Following the above thoughts, it is tempting to try to find out if PA21 has significant impact in the metabolic profile of the HD that receiving it.

This study was aimed to investigate sucroferric oxyhydroxide (PA21) in terms of efficacy and safety in HD patients with MBD and to assess the relationship between phosphate control, nutrition, anemia, lipids and a set of metabolic bone disease biomarkers in a cohort of adult patients with advanced dialysis-dependent CKD.

\section{Patients-methods}

In this prospective study $\mathrm{HD}$ stable patients with hyperphosphataemia were received PA21 for 44 weeks. Sucroferric oxyhydroxide was administered in the form of a brown chewable oral tablet as monotherapy. If necessary, the caring nephrologist adjusted the sucroferric oxyhydroxide dose based on the predialysis

${ }^{\star}$ Correspondence to: Griveas I, Consultant Nephrologist, Medical Director Nephrology Department Army Share Fund Hospital of Athens (NIMTS), Greece, Profesor-Advisor Hellenic Open University, Kifisias Ave, Chalandri, Athens, Greece, E-mail: giannisgriv@hotmail.com

Received: May 31, 2019; Accepted: June 07, 2019; Published: June 10, 2019 
serum phosphorus concentration every month in order to maintain the serum phosphorus concentration in the range of 3.5 to $5.5 \mathrm{mg} /$ dl. Concomitant use of other drugs having an effect on serum phosphorus concentrations; any oral iron agents; or any study drugs other than sucroferric oxyhydroxide. The use of i.v. iron was permitted if caring physician considered it necessary according to the protocols of the dialysis unit. The dosage of vitamin $\mathrm{D}$ receptor activators and calcimimetics was not changed throughout the study period wherever possible.

The primary outcome was estimation of serum phosphate concentration at the end of treatment. Secondary outcomes were monitoring of haematocrit $(\mathrm{Hct})$, hemoglobin $(\mathrm{Hb})$, corrected serum calcium, albumin, cholesterol, triglycerides, intact-parathyroid hormone $(\mathrm{PTH})$ concentrations during the study protocol. Ferritin levels were monitored also during our study period. Adverse events (AEs) and adverse drug reactions (ADRs) were also evaluated.

\section{Result}

A total of $31 \mathrm{HD}$ patients were enrolled in our study protocol. Mean administration of medication was 1-3 pills per day. 6 patients were totally withdrawn from the study (19.35\%). The reasons for discontinuation were diarrhea (5 patients after 2 months of treatment) and discolored feaces (one patient after also 2 months of treatment).

The demographic and clinical baseline characteristics of patients are shown in Table 1. Our patients had a mean age 61.35 years (range: 35-87 months) and were under replacement therapy for 48 months, range: 6-300 months.

9 patients were naïve regarding phosphate medication, 18 were receiving sevelamer before starting PA21 and 4 lanthanum.

From 31 patients of our study, 18 received oral VDRAs, 2 received i.v. VDRAs, 7 received cinacalcet and 9 patients did not receive either VDRAs or calcimimetics.

We noticed significant reduction of the phosphate levels even from the first month of treatment (from $6.54 \pm 1.27$ to $5.05 \pm 1.01 \mathrm{mg}$ / $\mathrm{dl}, \mathrm{p}<0.05$, approximately $23 \%$ reduction from baseline). This trend carried out until the end of the study period $(4 \pm 0.90 \mathrm{mg} / \mathrm{dl}, \mathrm{p}<0.05$, approximately $38 \%$ reduction from baseline). Remarkable finding was the significant reduction of PTH levels in all of our patients without interfering in vitamin $\mathrm{D}$ or calcimimetic supplementation after 6 months of therapy with PA21 (PTH at first $698 \pm 564 \mathrm{pg} / \mathrm{ml}, 6^{\text {th }}$ month $433 \pm 409 \mathrm{pg} / \mathrm{ml}, \mathrm{p}<0.05)$ which carried out until the end of the study protocol $(383 \pm 115 \mathrm{pg} / \mathrm{ml})$. Ferritin levels remained stable (from $460 \pm$

Table 1. Patient baseline and demographic characteristics (No 31) Characteristic Values

\begin{tabular}{|c|c|}
\hline Age, yr, mean (SD) & $\mathbf{6 1 . 3 5}$ years (range: $\mathbf{3 5 - 8 7}$ months) \\
\hline Sex, & $\mathrm{n}(\%)$ \\
\hline Male & $21(67.3)$ \\
\hline Female & $10(32.3)$ \\
\hline Primary disease, & $\mathrm{n}(\%)$ \\
\hline Diabetic nephropathy & $12(38.7)$ \\
\hline Chronic glomerulonephritis & $2(6,5)$ \\
\hline Nephrosclerosis & $12(38.7)$ \\
\hline Polycystic kidney disease & $1(3.2)$ \\
\hline Unknown & $4(12.9)$ \\
\hline Dialysis vintage, mo & $\mathrm{n}(\%)$ \\
\hline Mode of dialysis, & $24(77.4)$ \\
\hline Hemodialysis & $7(22.6)$ \\
\hline Hemodiafiltration & months, range: $6-300$ months. \\
\hline
\end{tabular}

254 to $524 \pm 256 \mathrm{mg} / \mathrm{dl}$ in the end, $\mathrm{p}=\mathrm{NS}$ ). 2 months since the beginning of the protocol we noticed increase in the levels of Hct (35.9\% vs 37.41 $\%, \mathrm{p}=0.097$ ) which remained stable until the end of the study period (37.47\%). Cholesterol levels tended to reduce during our notice period ( $175 \pm 34$ beginning vs $160 \pm 15$ at the end, $\mathrm{p}=0.213$ ). At the same time, albumin and triglycerides levels remained stable during the study period. Calcium levels had also unremarkable differences.

\section{Discussion}

During our study, hyperphosphatemia treatment with sucroferric oxyhydroxide (monotherapy) was found to successfully control serum phosphorus levels in HD patients who had received previously either other phosphate binders or who were naïve regarding this category of regimens. In addition, target levels were achieved by Week 4 , suggesting that this drug may have an early effect in terms of improvement in serum phosphorus levels.

In the above study firstly, we assessed the administration of PA21 in terms of safety and efficacy over 44 weeks under HD. Regarding the safety of long-term PA21 treatment, we observed that diarrhea was the most frequently reported ADR associated with PA21 treatment, and that most cases were mild, transient, and developed early during treatment. 5 patients discontinued the study because of diarrhea 2 months since the beginning of the medication. The low incidence of constipation may be an added benefit of treatment with PA21 because CKD patients undergoing dialysis are known to suffer from constipation secondary to water restriction [20]. Our notice comes together with data from the literature that confirm the fact that ADR of PA21 are mild, mainly concern loose stool and at the same time administration of PA21 is a safe therapeutic option $[17,21]$.

In the present study, we enrolled HD patients who had received phosphate binder therapy or were naïve regarding phosphate binders and tried to evaluate the efficacy of sucroferric oxyhydroxide for a 44 weeks period. As a result, sucroferric oxyhydroxide, at low doses and with decreased pill burden, was able to maintain serum phosphorus concentrations within the control target range [22] and was well tolerated either switching the treatment or starting phosphate binders for the first time.

The serum phosphorus concentration was controlled in most patients with rather low doses of sucroferric oxyhydroxide. The number of tablets of phosphate binder required decreased when patients switched from sevelamer to sucroferric oxyhydroxide; thus, the pill burden was mcu more less. A decreased pill burden is associated with a greater quality of life and improved patient adherence to treatment among hemodialysis patients with hyperphosphatemia [23]. As a consequence, lowering the pill burden may lead to risk mitigation for secondary hyperparathyroidism, renal osteodystrophy, and cardiovascular disease.

In our study population we also noticed a significant reduction of PTH levels, which remained until the end of the notice period. It is common knowledge that the majority of chronic dialysis patients have persistent hyperphosphatemia as well as hyperparathyroidism. The above fact makes them receive a list of medications. Because potential drug-drug interactions (which has not been studied in detail in most cases) may limit the therapeutic activity of other medications, the ideal phosphate binder should not only have a high selectivity for binding phosphate, minimal systemic absorption, and a good safety and tolerability profile but also minimal interaction with other medications or nutritional supplements [24]. It is also known that most 
HD patients are also prescribed either oral or parenteral vitamin $\mathrm{D}$ receptor agonists (VDRAs) [12]. Despite CKD-MBD is with anemia the most popular topics in the everyday clinical practice of nephrologists drug-drug interactions have not been studied in depth. It has been proposed that concomitant administration of phosphate binders with oral VDRAs may result in drug-drug interactions, thereby reducing the therapeutic activity of these oral VDRAs [12]. Preclinical studies have shown that sevelamer has a high affinity for bile acids, which may impair the absorption of fat-soluble vitamins, including vitamin $\mathrm{D}$ [25]. Our data agree with a previous sub-analysis which showed that sevelamer treatment interacted with oral VDRA affect iPTH levels, while sucroferric oxyhydroxide did not [24]. That could explain the significant reduction of PTH levels in our patients. Recent data showed that reduction in FGF 23 due to reductions of serum phosphorus concentrations provided by phosphate binder therapy could be an explanation of the above phenomenon [26].

Growing evidence support the idea that FGF23 may be more important than serum phosphorus, serum calcium, and PTH levels in the treatment of CKD-MBD [27]. Transcription of FGF23 has been reported to be enhanced by iron deficiency but not directly by serum phosphorus, serum calcium, or intact- PTH [28] and an animal study reported that sucroferric oxyhydroxide, which contains iron, decreased FGF23 to a significantly greater extent than either lanthanum carbonate or sevelamer hydrochloride [29]. To the best of our knowledge, this study is the first clinical report indicating that the improvement in iron deficiency associated with hyperphosphatemia treatment with sucroferric oxyhydroxide possibly contributes directly to the decrease in FGF23 levels. Increased $\mathrm{Hb}$ and ferritin levels were observed after administration of sucroferric oxyhydroxide, suggesting that the drug may act to improve renal anemia. Our notice agrees with recent data which suggest that hyperphosphatemia treatment with sucroferric oxyhydroxide improves renal anemia and various factors affecting the vital prognosis of $\mathrm{HD}$ patients (such as FGF23, serum phosphorus, $\mathrm{Hb}$ levels) but further investigation is expected.

The findings of the present study should be considered in light of several limitations. First, that was a study without a control group, and thus was subject to the introduction of bias. Second, only Greek patients were included, which limits the generalizability of the results to other populations. Third, the study had a relatively small sample size. However, our results are worth publishing. From our point of view these are real life data which demonstrate our experience regarding usage of PA21 in patients under HD with MBD. Our study was an intention to treat study, which reveals all the benefits of the drug in all aspects of MBD.

In conclusion, sucroferric oxyhydroxide is a valuable treatment option for hyperphosphataemia in CKD patients on dialysis, providing an effective and generally well tolerated noncalcium-based phosphate binder therapy with a low pill burden and the potential for improved treatment adherence in MBD in general. Apart from that, it seems that it helps HD patients holistically since it favours stability of Hct and nutrition improving lipids parameters at the same time.

\section{References}

1. Block GA (2001) Control of serum phosphorus: implications for coronary artery calcification and calcific uremic arteriolopathy (calciphylaxis). Curr Opin Nephrol Hypertens 10: 741-747. [Crossref]

2. Block GA, Klassen PS, Lazarus JM, Ofsthun N, Lowrie EG, et al. (2004) Mineral metabolism, mortality, and morbidity in maintenance hemodialysis. J Am Soc Nephrol 15: 2208-2218. [Crossref]
3. Palmer SC, Hayen A, Macaskill P, Pellegrini F, Craig JC, et al. (2011) Serum levels of phosphorus,parathyroid hormone, and calcium and risks of death and cardiovascular disease in individuals with chronic kidney disease: a systematic review and metaanalysis. JAMA 305:1119-1127. [Crossref]

4. Hutchison AJ (2009) Oral phosphate binders. Kidney Int 75: 906-914. [Crossref]

5. Locatelli F, Del Vecchio L, Violo L, Pontoriero G (2014) Phosphate binders for the treatment of hyperphosphatemia in chronic kidney disease patients on dialysis: a comparison of safety profiles. Expert Opin Drug Saf 13: 551-561. [Crossref]

6. Lopes AA, Tong L, Thumma J, Li Y, Fuller DS, et al. (2012) Phosphate binder use and mortality among hemodialysis patients in the Dialysis Outcomes and Practice Patterns Study (DOPPS): evaluation of possible confounding by nutritional status. Am J Kidney Dis 60: 90-101. [Crossref]

7. Fukagawa M, Yokoyama K, Koiwa F, Taniguchi M, Shoji T, et al. (2013) Clinical practice guideline for the management of chronic kidney disease-mineral and bone disorder. Ther Apher Dial 17: 247-288. [Crossref]

8. National Kidney Foundation (2003) K/DOQI clinical practice guidelines for bone metabolism and disease in chronic kidney disease. Am J Kidney Dis 42(4 suppl 3): S1-201. [Crossref]

9. KDIGO (2009) KDIGO Clinical Practice Guideline for the Diagnosis, Evaluation,Prevention, and Treatment of Chronic Kidney Disease-Mineral and Bone Disorder (CKD-MBD). Introduction and definition of CKD-MBD and the development of the guideline statements (PDF). Kidney Int 76(suppl 113): S3-S8.

10. Isakova T, Gutiérrez OM, Chang Y, Shah A, Tamez H, et al. (2009) Phosphorus binders and survival on hemodialysis. J Am Soc Nephrol 20: 388-396. [Crossref]

11. Lopes AA, Tong L, Thumma J, Li Y, Fuller DS, et al. (2012) Phosphate binder use and mortality among hemodialysis patients in the Dialysis Outcomes and Practice Patterns Study (DOPPS): evaluation of possible confounding by nutritional status. Am J Kidney Dis 60: 90-101. [Crossref]

12. Sprague SM, Coyne D (2010) Control of secondary hyperparathyroidism by vitamin D receptor agonists in chronic kidney disease. Clin J Am Soc Nephrol 5: 512-518. [Crossref]

13. Jablonski K, Chonchol M (2015) Management of mineral and bone disorders in chronic kidney disease patients. In: Kimmel PL, Rosenberg ME, 1st Ed. Chronic Renal Disease. New York, NY: Elsevier; 2015: 646-662.

14. Asmus HG, Braun J, Krause R, Brunkhorst R, Holzer H, et al. (2005) Two year comparison of sevelamer and calcium carbonate effects on cardiovascular calcification and bone density. Nephrol Dial Transpl 20: 1653-1661. [Crossref]

15. Drüeke TB (2007) Lanthanum carbonate as a first-line phosphate binder: the "cons". Semin Dial 20: 329-332. [Crossref]

16. Zaichick S, Zaichick V, Karandashev V, Nosenko S (2011) Accumulation of rare earth elements in human bone within the lifespan. Metallomics 3: 186-194. [Crossref]

17. Floege J, Covic AC, Ketteler M, Rastogi A4, Chong EM, et al. (2014) A phase III study of the efficacy and safety of a novel iron-based phosphate binder in dialysis patients. Kidney Int 86: 638-647. [Crossref]

18. Floege J, Covic AC, Ketteler M, Mann JF, Rastogi A, et al. (2015) Long-term effects of the iron-based phosphate binder, sucroferric oxyhydroxide, in dialysis patients. Nephrol Dial Transpl 30: 1037-1046. [Crossref]

19. Koiwa F, Terao A (2016) Dose-response efficacy and safety of PA21 in Japanese hemodialysis patients with hyperphosphatemia: a randomized, placebo controlled, double-blind, Phase II study. Clin Exp Nephrol 21:513-522. [Crossref]

20. Dong R, Guo ZY, Ding JR, Zhou YY, Wu H (2014) Gastrointestinal symptoms: a comparison between patients undergoing peritoneal dialysis and hemodialysis. World $J$ Gastroenterol 20: 11370-11375. [Crossref]

21. Koiwa F, Yokoyama K, Fukagawa M, Akizawa T (2017) Long-Term Assessment of the Safety and Efficacy of PA21 (Sucroferric Oxyhydroxide) in Japanese Hemodialysis Patients With Hyperphosphatemia: An Open-Label,Multicenter, Phase III Study. J Ren Nutr 27: 346-354. [Crossref]

22. National Kidney Foundation (2017) Kidney Disease Outcomes Quality Initiative (KDOQI) Clinical Practice Guidelines for Bone Metabolism and Disease in Chronic Kidney Disease. Available at: http://www2.kidney.org/professionals/kdoqi/guidelines bone/guide3.htm.

23. Chiu YW, Teitelbaum I, Misra M, de Leon EM, Adzize T, et al. (2009) Pill burden, adherence, hyperphosphatemia, and quality of life in maintenance dialysis patients Clin J Am Soc Nephrol 4: 1089-1096. [Crossref] 
24. Sprague SM, Covic A, Floege J, Ketteler M, Botha J, et al. (2016) Pharmacodynamic Effects of Sucroferric Oxyhydroxide and Sevelamer Carbonate on Vitamin D Receptor Agonist Bioactivity in Dialysis Patients. Am J Nephrol 44:104-112. [Crossref]

25. Braunlin W, Zhorov E, Guo A, Apruzzese W, Xu Q, et al. (2002) Bile acid binding to sevelamer HCl. Kidney Int 62: 611-619. [Crossref]

26. Ketteler M, Sprague SM, Covic A, Rastogi A, Spinowitz B, et al. (2018) Effects of sucroferric oxyhydroxide and sevelamer carbonate on chronic kidney diseasemineral bone disorder parameters in dialysis patients. Nephrol Dial Transplant 1-8. [Crossref]
27. Oliveira RB, Cancela AL, Graciolli FG, Dos Reis LM, Draibe SA, et al. (2010) Early control of PTH and FGF23 in normophosphatemic CKD patients: a new target in CKDMBD therapy? Clin J Am Soc Nephrol 5: 286-291. [Crossref]

28. Wolf M, Koch TA, Bregman DB (2013) Effects of iron deficiency anemia and its treatment on fibroblast growth factor 23 and phosphate homeostasis in women. J Bone Miner Res 28: 1793-803. [Crossref]

29. Phan O, Maillard M, Malluche HH, Stehle JC, Funk F, et al. (2015) Effects of sucroferric oxyhydroxide compared to lanthanum carbonate and sevelamer carbonate on phosphate homeostasis and vascular calcifications in a rat model of chronic kidney failure. Biomed Res Int 2015: 515606.

Copyright: (C2019 Griveas I. This is an open-access article distributed under the terms of the Creative Commons Attribution License, which permits unrestricted use, distribution, and reproduction in any medium, provided the original author and source are credited. 